\title{
Compulsive Internet use and workaholism: An exploratory two-wave longitudinal study
}

ARTICLE in COMPUTERS IN HUMAN BEHAVIOR • DECEMBER 2016

Impact Factor: 2.69 · DOI: 10.1016/j.chb.2016.02.060

READS

19

3 AUTHORS, INCLUDING:

\section{Cristina Quinones}

The Open University (UK)

14 PUBLICATIONS 14 CITATIONS

SEE PROFILE

\section{Mark D Griffiths}

Nottingham Trent University

754 PUBLICATIONS 15,067 CITATIONS

SEE PROFILE 
Compulsive Internet use and workaholism: An exploratory two-wave longitudinal study

Cristina Quinones ${ }^{\mathrm{a}}$

Mark D. Griffiths ${ }^{\mathrm{b}}$

Nada Kakabadse ${ }^{c}$

aOpen University Business School, Walton Hall, Milton Keynes, MK7 6AA, United Kingdom. Email address: cristina.quinones@open.ac.uk. Telephone number +4401908 632763. Corresponding author

${ }^{b}$ Nottingham Trent University, College of Business Law \& Social Sciences, School of Social Science, Nottingham, UK. Email address: mark.griffiths@ntu.ac.uk.

${ }^{\mathrm{c}}$ Henley Business School, Greenlands Campus, Henley, Reading-on-Thames,RG9 3AU, United Kingdom. Email address: n.kakabadse@ henley.ac.uk. 


\begin{abstract}
Workaholism refers to the uncontrollable need to work and comprises working compulsively (WC) and working excessively (WE). Compulsive Internet Use (CIU), involves a similar behavioural pattern although in specific relation to Internet use. Since many occupations rely upon use of the Internet, and the lines between home and the workplace have become increasingly blurred, a self-reinforcing pattern of workaholism and CIU could develop from those vulnerable to one or the other. The present study explored the relationship between these compulsive behaviours utilizing a two-wave longitudinal study over six months. A total of 244 participants who used the Internet as part of their occupational role and were in full-time employment completed the online survey at each wave. This survey contained previously validated measures of each variable. Data were analysed using cross-lagged analysis. Results indicated that Internet usage and CIU were reciprocally related, supporting the existence of tolerance in CIU. It was also found that CIU at Time 1 predicted WC at Time 2 and that WE was unrelated to CIU. It is concluded that a masking mechanism appears a sensible explanation for the findings. Although further studies are needed, these findings encourage a more holistic evaluation and treatment of compulsive behaviours.
\end{abstract}

Keywords: Compulsive Internet Use; Workaholism; Working Compulsively, Internet Use; Longitudinal study; Cross-lagged study 
Compulsive Internet use and workaholism:

An exploratory two-wave longitudinal study

\section{Introduction}

McKinsey Global Institute's (2011) pioneering study reported that the Internet accounted for $21 \%$ of GDP growth over the last five years among the developed countries (i.e. consumption, supply, and job creation), with two-thirds of this growth falling outside the technology sector. The report concluded that companies' competitive advantage depends to a great extent on how they exploit Internet opportunities. In the UK, an estimated $90 \%$ of jobs require at least some level of digital literacy skills and frequent use of Internet-enabled tools back (Knight, 2011). Within this context, the pervasive presence of the Internet within organizations is unlikely to diminish. Sophisticated but increasingly accessible technology has also transformed the traditional boundaries between home, and the workplace enabling many employees to adopt flexible work arrangements including working from home (Maitland, \& Thomson, 2011). Although the latter has advantages such as increasing perceived control over one's work (e.g., Mazmanian, Orlikowski, \& Yates, 2013), it can also threaten an employee's physical and psychological wellbeing. Consequently, psychological detachment during out-ofwork hours has become more challenging for many, with mobile devices (such as Wi-Fi enabled laptops, tablets, and smartphones) contributing to semi-automatic responses that bypass conscious differentiation between ability to respond and obligation to do so (Barber \& Jenkins, 2014; Derks, van Mierlo, \& Schmitz, 2014; Porter \& Kakabadse, 2006; Sonnentag, Binnewies, \& Mojza, 2008). This development, together with the rise in the costs of living that is often unmatched with proportional growth in wages, is contributing to greater work intensification (Kakabadse, Kouzmin \& Kakabadse, 2000). Within this context, it has been argued that those with vulnerability to either working compulsively, or using the Internet 
compulsively, could develop both problematic behaviours in a self-reinforcing cycle pattern (Porter \& Kakabadse, 2006).

Working long hours, beyond what is expected in order to meet reasonable work goals is a central element of 'workaholism' (e.g. Porter \& Kakabadse, 2006). In addition to working excessively, Oates' (1971) original definition also suggests a compulsive way of working in that there is an "uncontrollable need to work incessantly" (p.11). Based on this, researchers commonly conceptualize workaholism in terms of two dimensions. These are a cognitive dimension of obsession with work or 'working compulsively' and a behavioral dimension of ‘working excessively’ (e.g. Schaufeli et al., 2009). Research into workaholism has steadily increased, and the negative consequences on employee wellbeing have been widely reported (e.g., Andreassen, Griffiths, Hetland \& Pallesen, 2012; Andreassen, Ursin, \& Eriksen, 2007; Burke, 2001; Griffiths \& Karanika-Murray, 2012; van Beek, Taris \& Schaufeli, 2011).

In contrast, Compulsive Internet Use (CIU) is a more recent phenomenon, which nonetheless displays a similar behavioural pattern to working compulsively. Compulsive internet use refers to the "pattern of internet use characterized by loss of control, preoccupation, conflict, withdrawal symptoms, and use of the Internet as a coping strategy" (Meerkerk et al., 2010, p. 729). Debates as to whether this maladaptive behavior should be called "addiction" are still ongoing. Those against the use of the term argue that this can result in the trivialization of the devastating impact of substance-based dependencies. However, the definition and operationalization of CIU builds on and reflects the key dimensions of the most widely accepted model of behavioural addictions (Orford, 1985; Buckner, Castille, \& Sheets, 2012; Caplan, 2003; Young, 1998). Importantly, like compulsive workers, who experience loss of control over work and interpersonal conflict [e.g., Bakker, Burke, \&, Demerouti, 2009], compulsive Internet users experience a loss of control over their Internet use and conflicts with their personal and working lives (Casale, Fioravanti, Flett, \& Hewitt, 2015; Greenfield, 1999; 
Griffiths, 2000; 2010a; Kuss, Griffiths, Karila \& Billieux, 2014; Meerkerk, van den Eijnden, Franken, \& Garretsen, 2010).

Workaholics' urges are becoming ever easier to fulfil thanks to technology advancements (Porter, 2001; Ng, Sorensen \& Feldman, 2007). Simultaneously, constant Internet access at work, may facilitate compulsive use in those individuals highly engaged with it in their personal lives (Porter \& Kakabadse, 2003). In addition to enhancing problematic behaviours, some authors have argued that both workaholism and CIU could be causally related (Porter \& Kakabadse, 2006). In fact, there is preliminary evidence showing the existence of mutually reinforcing cycle of CIU and workaholism (Porter \& Kakabadse, 2003). However, to the present authors' knowledge, such a relationship has only ever been demonstrated in one qualitative study. Therefore, the first objective of the present study was to explore the extent to which reciprocal relationships between CIU and workaholism actually exist utilizing a twowave longitudinal design. Furthermore, since the CIU literature relies largely on cross-sectional data, and little is known about the temporal relationships of commonly discussed correlates, the present study explored the relationships between CIU and hours of Internet use, whilst controlling for the Big Five personality factors.

\section{Literature Review}

Emerging evidence has demonstrated that addictions (both chemical and behavioural) share similar courses, histories, and neurobiological correlates (Orford, 2001; Grant, Potenza, Weinstei \& Gorelick, 2010; Volkow, 2005). This has encouraged researchers to study patterns of co-occurrence as this can lead to adopt a holistic approach to prevent and treat such problems effectively (Shaffer et al., 2004). However, studies reporting co-occurrence of multiple addictions are scarce, and those that exist, have traditionally relied on teenage samples. A notable exception is that of Sussman, Lisha, and Griffiths (2011) who conducted a meta- 
analysis with (mainly) US adult populations. The authors estimated that around $47 \%$ of the American population experience an addiction to one of eleven substance and behaviours over a 12 -month period, and found $23 \%$ of co-occurrence between two or more of these addictions (i.e., cigarettes, alcohol, hard drugs and the behavioral included eating, gambling Internet, shopping, love, sex, exercise and work). Based on methodologically flawed literature, the authors tentatively estimated that Internet addicts had a 10\% chance of also being workaholics, and that workaholics had a $20 \%$ chance of being Internet addicts. However, since that study was published, there has been a significant increase in research into both Internet addiction (Kuss et al., 2014) and workaholism (Andreassen et al., 2014).

The addiction literature suggests that excessive appetite for a particular object often coexist with appetite for another one if both objects are frequently found in the same context simultaneously (Griffiths, 2005; Miller, 1980; Orford, 2001). For instance, coffee, which can be found at work and at home, can aid alertness and productivity. Workaholism and coffee drinking often co-occur, and when they do, they likely reinforce each other (Porter \& Kakabadse, 2006). Similarly, work and technology are often intertwined and work is reliant on the use of technology. It has also been suggested that excessive use of technology can be justified through work (Porter, 2001). In this sense, problems controlling the engagement in one behaviour, may be related to problems in the other. Both workaholism and CIU have been extensively studied separately (e.g., Griffiths, 2010; Meerkerk et al., 2010; Ng et al., 2007), however, studies examining co-occurrence are scarce. An exception to this are the studies conducted by Porter and Kakabadse $(2003,2006)$. The authors conducted a qualitative study with IT professionals and concluded that compulsive work and compulsive Internet use were mutually reinforcing each other. The actual mechanisms explaining mutual causation beyond shared exposure were not really unpacked by these authors. In order to understand potential mechanisms between these two behaviours the present authors build on the syndrome model 
of addiction (Shaffer et al., 2004; Kuss et al., 2014) and more specifically in the addiction interaction model (Carnes et al., 2005).

According to Shaffer et al. (2004), exposure, degree of accessibility, and interaction with a specific object will determine the type of addiction a vulnerable individual is likely to develop. The model predicts that those individuals who develop an addiction (behavioural or chemical) experience an alteration of their reward system that increases their likelihood of developing new ones in relation to objects that they are frequently exposed to (Shaffer et al., 2004). Similarly, Sussman et al. $(2011,2012)$ argue that the type of behavioural addiction individuals are likely to develop following a previous one can be predicted from the individuals' lifestyles. It follows that those who exhibit compulsive working patterns, within contemporary working environments (where they are also highly exposed and in constant interaction with Internet), could well be at potential risk of developing compulsive Internet use. This could also happen the other way around. Thus, those who display compulsive Internet behaviour who also use the Internet for work purposes might end up developing compulsive working patterns (Porter \& Kakabadse, 2006).

Carnes et al.'s (2005) model of addiction interaction disorder explores different mechanisms that may explain how two or more addictions appear linked in a given individual, and not only co-occur but reinforce each other becoming "packages". A particularly interesting process that might be relevant in the case of work and the Internet use is the masking process. This mechanism describes how individuals engage in a more socially acceptable addiction as a strategy to hide or cover an addiction that is less socially acceptable. As opposed to CIU, workaholism is socially acceptable and even rewarded, to the extent to which the individual could be enhancing long-term family wellbeing. In this sense, Sussman, Arpawong, Sun, Tsai, Rohrbach, and Sprutjt-Metz (2014) argue that this is a 'nurturance' type of addiction. In contrast, CIU would sit more comfortably in the 'pleasure seeking' type of addictions. 
Nurturance-related behaviours, even when problematic, are more socially accepted. Whereas individual pleasure seeking motives, especially to the detriment of need satisfaction of significant others, are not (Schwartz, 2010).

It was argued above that interpersonal conflict is a key dimension of compulsive Internet use. Thus, the excessive engagement with the Internet leaves less time to interact with meaningful others and thereby creating conflict in the interpersonal relationships. Loss of control over the Internet use (the amount of use and the suitability of the moment) is another key characteristic of the problem. For those in employment, compulsive Internet use is likely to translate into problems at work as well as problems with their families and they will need a way to cope, which by definition will be related to more engagement with the object of addiction (Griffiths, 2005). In extreme cases, similar to other behavioural or substance addictions, individuals cope by quitting their jobs so that they have more time to engage with online activities. The present authors argue that in less extreme cases, individuals may find more adaptive ways of coping such as the described in the masking process. Thus, in those individuals who use the Internet for work, a sensible coping mechanism could be increasing their engagement on the nurturance object (in this case, work). If pure masking occurred, a one-direction causation path between compulsive internet use and working compulsively would be expected. This would be in line with those who defend the catalyst function of the Internet in relation to the intensification of other behavioural addictions (Carnes et al., 2005).

Carnes et al (2005) argued that an alternative mechanism might explain a potential interaction between two addictions (i.e., fusion). Though the rationale behind masking might equally explain initial engagement in nurturance-type behaviour, eventually these two behaviours might end up reinforcing each other. This suggests a reciprocal relationship between working compulsively and CIU. In view of the competing theoretical mechanisms, and the limited evidence available, the objective of the exploratory present study was to 
investigate the extent to which a process of masking versus a process fusion explained the relationship between workaholism and compulsive Internet use. In addition to this, and to overcome the excessive reliance on cross-sectional studies in the CIU literature, the present study also tested cross-lagged reciprocal effects in the relationship between CIU and hours of Internet use.

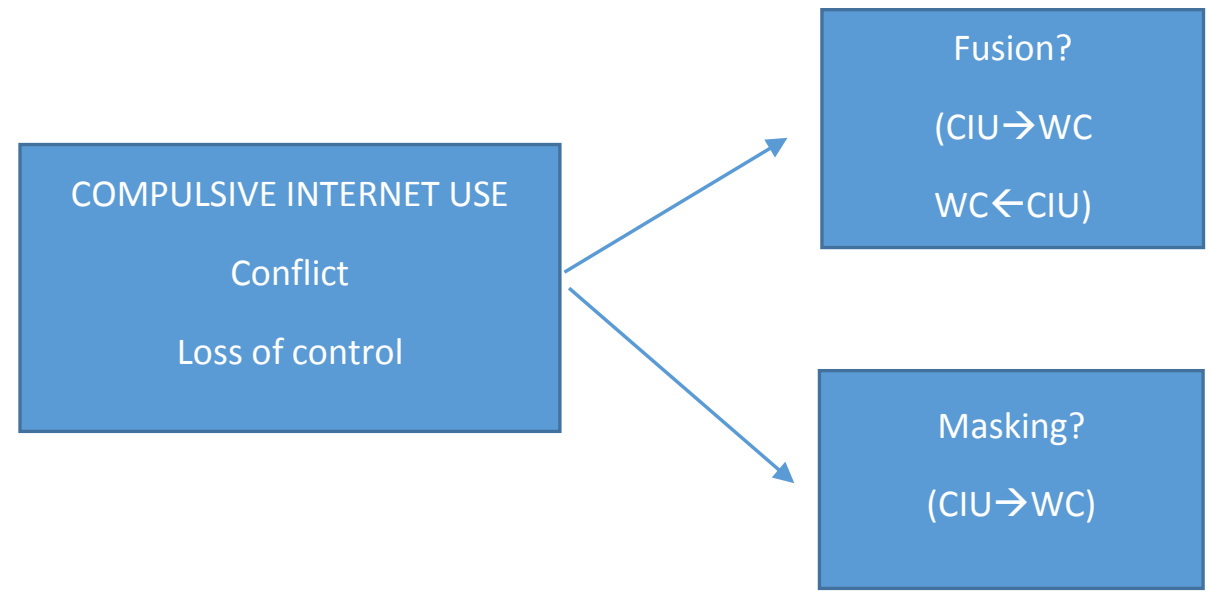

Figure 1. Patterns of co-occurrence of compulsive work and Internet use

\section{Method}

\subsection{Participants and procedure}

Data were collected from 516 participants at Time 1 (259 male, $\mathrm{M}_{\mathrm{age}}=45.07$ years; $\mathrm{SD}=13.70 ; 257, \mathrm{M}_{\mathrm{age}}=38$ years, $\left.\mathrm{SD}=14.5\right)$. A total of 244 people from the original sample agreed to participate in the second wave six months later (47\%) (129 male, 115 female; $\mathrm{M}_{\mathrm{age}}=$ 43.59 years; $\mathrm{SD}=13.88$ ). Data were gathered through an online survey and participants were drawn from a market research panel. The market research company was asked to recruit participants from a wide range of ages and occupations, and were asked to provide a balanced sample of male and female workers. They were also asked to confirm that the participants use 
the Internet in their jobs and that they were in full-time employment, as these were the minimum requirements to test less extreme forms of coping through masking. Table 1 summarises the composition of the final sample of the study including relevant demographic data as well as data about their use of the Internet for private purposes:

Table 1.Demographic variables and online habits

Variables Frequency $\%$ Mean SD Job title

Administrative $43 \quad 18$

Logistics and Operations

$31 \quad 13$

Customer Services \& Sales

$21 \quad 9$

Management and administration

$20 \quad 8$

HR

125

Accounting, Finance \& Legal

114

Communication, PR and Marketing

$15 \quad 6$

IT

$18 \quad 7$

Maintenance

31

Engineering, Research \& Development

$34 \quad 14$

Teaching

$7 \quad 3$

Healthcare

229

Not disclosed

$7 \quad 3$

Ethnicity

White British/Any other white background

$223 \quad 91$

Mixed/multiple ethnic groups

$5 \quad 2$

Asian/Asian British

$11 \quad 5$

Black African/Black Caribbean/Black British

$3 \quad 1$

Other ethnic group

21

Gender

$\begin{array}{lll}\text { Female } & 115 & 47\end{array}$

Male $\quad 129 \quad 53$

Highest qualification achieved

$\begin{array}{lll}\text { Postgraduate } & 22 & 9\end{array}$

$\begin{array}{lll}\text { First degree } & 48 & 20\end{array}$

$\begin{array}{lll}\text { A-Levels } & 37 & 15\end{array}$

Diploma of Higher Education $\quad 13 \quad 5$

HND/HNC $12 \quad 5$

NVQ/SVQ $\quad 25010$

GSCEs $\quad 60 \quad 25$

$\begin{array}{lll}\text { No qualification } & 21 & 9\end{array}$

$\begin{array}{lll}\text { Other qualification } & 6 & 2\end{array}$

Relationship status

Single

$81 \quad 33$ 
Divorced

$\begin{array}{cc}30 & 12 \\ 2 & 1 \\ 54 & 22 \\ 100 & 41 \\ 39 & 16 \\ 18 & 7 \\ & \\ 23 & 10 \\ 167 & 68 \\ 27 & 11 \\ 27 & 11\end{array}$

Activities most frequently engaged whilst online (outside work)

General browsing

$82 \quad 34$

Social networking

Email

4920

Job searching

$15 \quad 6$

Shopping online/Ebay

$15 \quad 6$

News and sports

$14 \quad 5.7$

Gaming and gambling

$10 \quad 4$

Watching TV online

$3 \quad 1.2$

Blogging

$3 \quad 1.2$

Video surfing

$\begin{array}{ll}2 & .9\end{array}$

Hours online outside work

$\begin{array}{lcc}1-3 & 158 & 65 \\ 4-5 & 52 & 21 \\ 6-8 & 24 & 10 \\ 9+ & 10 & 4\end{array}$

Length of employment

$14.98 \quad 14.99$

\subsection{Sample attrition}

Participants who participated in both waves of the study $(n=244)$ did not differ significantly from those who only participated in the first wave $(n=272)$ in terms of gender distribution $\left(\chi^{2}[1, \mathrm{n}=516]=p=.19\right)$ and ethnicity $\left(\chi^{2}[4, \mathrm{n}=516]=p=.69\right)$. However, $\mathrm{t}$-tests revealed significant differences in age $(\mathrm{t}[516]=-3.54, p<.01)$ with the attrition group's mean lower $(M=39)$ than the group of participants present in the two waves (M=43). Subsequently, in line with Goodman and Blum (1996), multiple logistic regression analysis was used to explore the non-random sampling bias in the variables of study. A dummy variable was created where $1=$ present in two waves, $0=$ attrition cases, and this was regressed on the key variables 
of study. There were no statistically significant coefficients in any of the study variables which supports the lack of random sampling problem.

\subsection{Materials}

Compulsive Internet Use was assessed using Meerkerk et al.’s (2010) 14-item scale. The scale included items such as: "How often do you feel depressed or irritated when you cannot use the Internet?” Items were rated on a 5-point scale ranging from 1 (strongly disagree) to 5 (strongly agree). Items were mean averaged for each scale. Workaholism was assessed using Schaufeli et al.'s (2009a) 10-item scale. The scale assesses two dimensions: working excessively (5 items) and working compulsively (5items). The 4-point scale ranges from 1 (never) to 4 (almost always). A sample item for working excessively was 'I find myself continuing work after my co-workers have called it quits' and for working compulsively 'It's important for me to work hard even when I don't enjoy what I'm doing.' Various studies have reported significant associations between Big 5 and CIU. The strongest correlate of CIU is neuroticism, whereas relationships with the remaining Big Five are somewhat inconsistent across studies (e.g., Charlton \& Danforth, 2009; Kuss, Griffiths, Karila \& Billieux, 2014 ; Landers, \& Lounsbury, 2006; Meerkerk et al., 2010; Nithya, \& Julius, 2007; Van der A et al., 2006). With regards to workaholism, the strongest correlations are with neuroticism and conscientiousness (e.g., Burke et al., 2001). Thus, the present study controlled for all Big Five factors. The Mini-IPIP scales were used (Donnellan et al., 2006). Each is made up of four items and are rated on a 5-point scale ranging from 1 (strongly disagree) to 5 (strongly agree).

Although these short scales may present a lower internal consistency (.60 upwards), the authors of the scale found that they still demonstrated good convergent and predictive validity with the family of variables on psychological distress and wellbeing, and did not exhibit significantly poorer results than longer measures of the Big Five with higher reliability values. 
Hence, it is argued that the lower internal consistency of the scales is acceptable to avoid overload, particularly in cases where individuals were asked to complete the survey multiple times. Considering that the present study was two-wave, and that the key purpose was to explore the predictive value of focal variables on each other (i.e., workaholism and compulsive Internet use) whilst partialling out the impact of these personality variables, these instruments are a suitable alternative to longer instruments. Cronbach's alphas are presented in Table 2 for all scales used in the present study.

\subsection{Analytical strategy}

Data were analysed using cross-lagged analyses (e.g., Burkholder \& Harlow, 2003). All variables of study were included at both times as this allows an estimation of potential reciprocal relationships between variables. The model contains auto-regressive paths (straight paths between the same variable at the two points in time; see Figure 2) and cross-lagged paths (diagonal paths between the independent variable of study at Time 1 and the dependent variable at Time 2; see Figure 2). Contemporaneous variables are allowed to correlate with one another eliminating the potential inflation of time-related estimates. All these paths were estimated simultaneously with AMOS 20. This allowed the authors to test the extent to which an independent variable at Time $\mathrm{t}$ predicts an outcome at Time $\mathrm{t}+1$, whilst controlling for the dependent variable at Time $\mathrm{t}$ (Lin \& Leung, 2010).

In line with other cross-lagged studies (de Lange, Taris, Kompier, Houtman, \& Bongers, 2004; Zacher \& de Langue, 2011) and to avoid the problems of under-identification and insufficient power associated with including all items (Schumacker \& Lomax, 1996), scale and latent variables were treated as identical (DeLange et al., 2004). Notwithstanding, the twostep approach was followed whereby the measurement model is tested prior to the structural 
model at both times. Analysis confirmed that the measurement models were consistent across time.

\section{Results}

The means and inter-correlations of the variables of study across the two waves are presented in Table 2. The test-retest coefficients were higher for CIU than for any other variable $(\mathrm{r}=.75, p<.01)$. Out of all control variables (i.e., Big Five), only neuroticism and conscientiousness were related to CIU and none was significantly related to any of the workaholism dimensions (i.e., working compulsively and excessively). 
Table 2. Correlations between Time 1 and Time 2 study variables

\begin{tabular}{|c|c|c|c|c|c|c|c|c|c|c|c|c|c|c|c|c|c|c|}
\hline $\begin{array}{l}\text { Variables } \\
\text { 1.Introv.T1 }\end{array}$ & 1 & 2 & 3 & 4 & 5 & 6 & 7 & 8 & 9 & 10 & 11 & 12 & 13 & 14 & 15 & 16 & 17 & 18 \\
\hline $\begin{array}{l}\text { 1.Introv.T1 } \\
\text { 2.Neurot.T1 }\end{array}$ & $.310^{* * *}$ & & & & & & & & & & & & & & & & & \\
\hline 3.Consc..T1 & .098 & $-.138^{*}$ & & & & & & & & & & & & & & & & \\
\hline 4.Aggreab.T1 & $.175^{* *}$ & .099 & $.435^{* *}$ & & & & & & & & & & & & & & & \\
\hline 5.Open.T1 & -.087 & -.047 & $.341^{* *}$ & $.227^{* *}$ & & & & & & & & & & & & & & \\
\hline 6.WorkExc.T1 & .005 & $.165^{* *}$ & .082 & .039 & $.223^{* * *}$ & & & & & & & & & & & & & \\
\hline 7.WorkCo.T1 & .087 & .113 & $.144^{*}$ & .108 & $.179^{* *}$ & $.712^{* *}$ & & & & & & & & & & & & \\
\hline 8.HoursT1 & .013 & .062 & -.093 & .017 & .030 & .069 & -.029 & & & & & & & & & & & \\
\hline 9.CIU.T1 & .053 & $.356^{* *}$ & $-.314^{* *}$ & -.101 & .084 & $.350^{* *}$ & $.213^{* *}$ & $.237^{* *}$ & & & & & & & & & & \\
\hline 10.Introv.T2 & $.523^{* * *}$ & $.143^{*}$ & -.100 & -.023 & $-.198^{* *}$ & $-.158^{*}$ & -.083 & .034 & -.059 & & & & & & & & & \\
\hline 11.Neurot.T2 & $.215^{* *}$ & $.494^{* * *}$ & $-.289^{* *}$ & -.067 & $-.184^{* *}$ & .118 & .046 & .070 & $.317^{* *}$ & $.264^{* *}$ & & & & & & & & \\
\hline 12.Consc.T2 & .040 & -.096 & $.483^{* *}$ & .095 & .058 & .039 & .087 & -.046 & $-.204^{* *}$ & -.101 & $-.246^{* * *}$ & & & & & & & \\
\hline 13.Aggreab.T2 & .070 & .064 & $.143^{*}$ & $.337^{* *}$ & .097 & .049 & $.145^{*}$ & -.011 & -.032 & -.109 & -.022 & .103 & & & & & & \\
\hline 14.Open.T2 & .006 & $.131^{*}$ & .068 & $.190^{* *}$ & $.314^{* * *}$ & .116 & $.127^{*}$ & -.060 & .083 & -.015 & .066 & .110 & $.440^{* *}$ & & & & & \\
\hline 15.WorkEx.T2 & -.005 & .049 & .086 & -.095 & $.146^{*}$ & $.646^{* *}$ & $.547^{* *}$ & -.054 & $.210^{* *}$ & $-.170^{* *}$ & -.040 & -.013 & -.004 & .046 & & & & \\
\hline 16.WorkCoT2 & .032 & .109 & .118 & -.035 & .091 & $.512^{* * *}$ & $.625^{* *}$ & -.084 & $.215^{* *}$ & -.095 & -.024 & .058 & .035 & .024 & $.732^{* *}$ & & & \\
\hline 17.Hours.T2 & -.019 & .106 & -.069 & .068 & -.029 & .100 & .083 & $.420^{* *}$ & $.292^{* *}$ & .014 & .008 & -.078 & -.020 & -.008 & -.029 & -.015 & & \\
\hline 18.CIU.T2 & .051 & $.248^{* *}$ & $-.269^{* *}$ & -.078 & .045 & $.261^{* *}$ & $.180^{* * *}$ & $.234^{* *}$ & $.755^{* *}$ & .008 & $.277^{* *}$ & $-.194^{* *}$ & -.070 & -.008 & $.257^{* *}$ & $.235^{* *}$ & $.333^{* * *}$ & \\
\hline M & 3.69 & 3.06 & 4.43 & 4.20 & 3.95 & 2.44 & 2.46 & 3.51 & 2.41 & 3.28 & 3.08 & 3.50 & 3.74 & 3.50 & 2.41 & 2.48 & 3.34 & 2.34 \\
\hline SD & 1.34 & 1.29 & 1.09 & 1.13 & 1.15 & .66 & .68 & 2.80 & .85 & .91 & .79 & .71 & .76 & .74 & .70 & .68 & 2.19 & .084 \\
\hline$\alpha$ & .70 & .67 & .60 & .61 & .57 & .80 & .77 & N/a & .94 & .70 & .67 & .62 & .76 & .60 & .80 & .78 & N/a & .94 \\
\hline
\end{tabular}

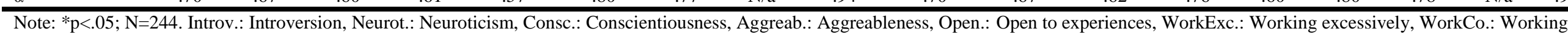
compulsively, Hours: Hours of use; CIU: Compulsive Internet Use 
The relationships between CIU, workaholism, and hours of usage were tested with nested models (see Table 3). First, the baseline model was tested with autoregressive paths (i.e. stability model). Second, cross-lagged effects were added in different steps. Thus, the analysis started by drawing cross-lagged paths between CIU at Time 1 and WE and WC at Time 2 (M2). A model was then fitted with cross-lagged paths between WE and WC at Time 1, and CIU at Time 2 (M3). Subsequently, a model was tested with reciprocal cross-lagged paths between both dimensions of workaholism and CIU (M4). The chi-square statistic difference was used to test whether a more complex model was better than simpler models (i.e., a model with fewer parameter estimates). Model $2\left(\mathrm{CIU}_{\mathrm{T} 1} \rightarrow \mathrm{WE}_{\mathrm{T} 2}, \mathrm{WC}_{\mathrm{T} 2}\right)$ had a significantly better fit than the model that only included autoregressive paths (M1). In contrast, Model 3 (WET1, $\mathrm{W}_{\mathrm{CT} 1} \rightarrow \mathrm{CIU}_{\mathrm{T} 2}$ ) was not significantly better than Model 1. Comparison between M1 and M4 (i.e. reciprocal causation model) revealed that M4 had a significantly better fit than M1. Since M3 was not better than M1 in the previous comparison, significant differences were due to the path from CIU to workaholism and not vice-versa. In view of this, reciprocal causation was rejected and M2 was used as a baseline model for further model comparisons. M5 included a cross-lagged path from Hours at Time 1 to CIU at Time 2 and the chi-square difference revealed that this model was significantly better than M2. Likewise, M6 (path from CIU 1 to Hours at Time 2) was also significantly better. Although reciprocity was likely here, the fit of a reciprocal model was compared to $\mathrm{M} 2$, and this yielded significant differences.

An equality constraint was added to the reciprocity model (M8) to confirm whether one path was dominant over the other in this reciprocal relationship. The equality constrain improved model fit, therefore these paths are unequal, and one is predominant. The indices of the direction from Hours of use at Time 1 to CIU at Time 2 are better than the other way around. Overall, in terms of chi-square in relation to degrees of freedom and fit indices, Model 7 had the best fit. The non-significant paths were deleted from the final model shown in Figure 2. In 
short, mutual causation was not confirmed, instead, CIU at Time 1 was related to increased working compulsively at Time $2(\beta=.121, p<.05)$ but not the other way around. Furthermore, CIU was not related to the working excessively dimension of workaholism. However, a reciprocal relationship was confirmed between hours of use and CIU, although there appeared to be a higher dominance on the effect of CIU on hours of use $(\beta=.201, \mathrm{p}<.05)$. 
TIME 1

TIME 2

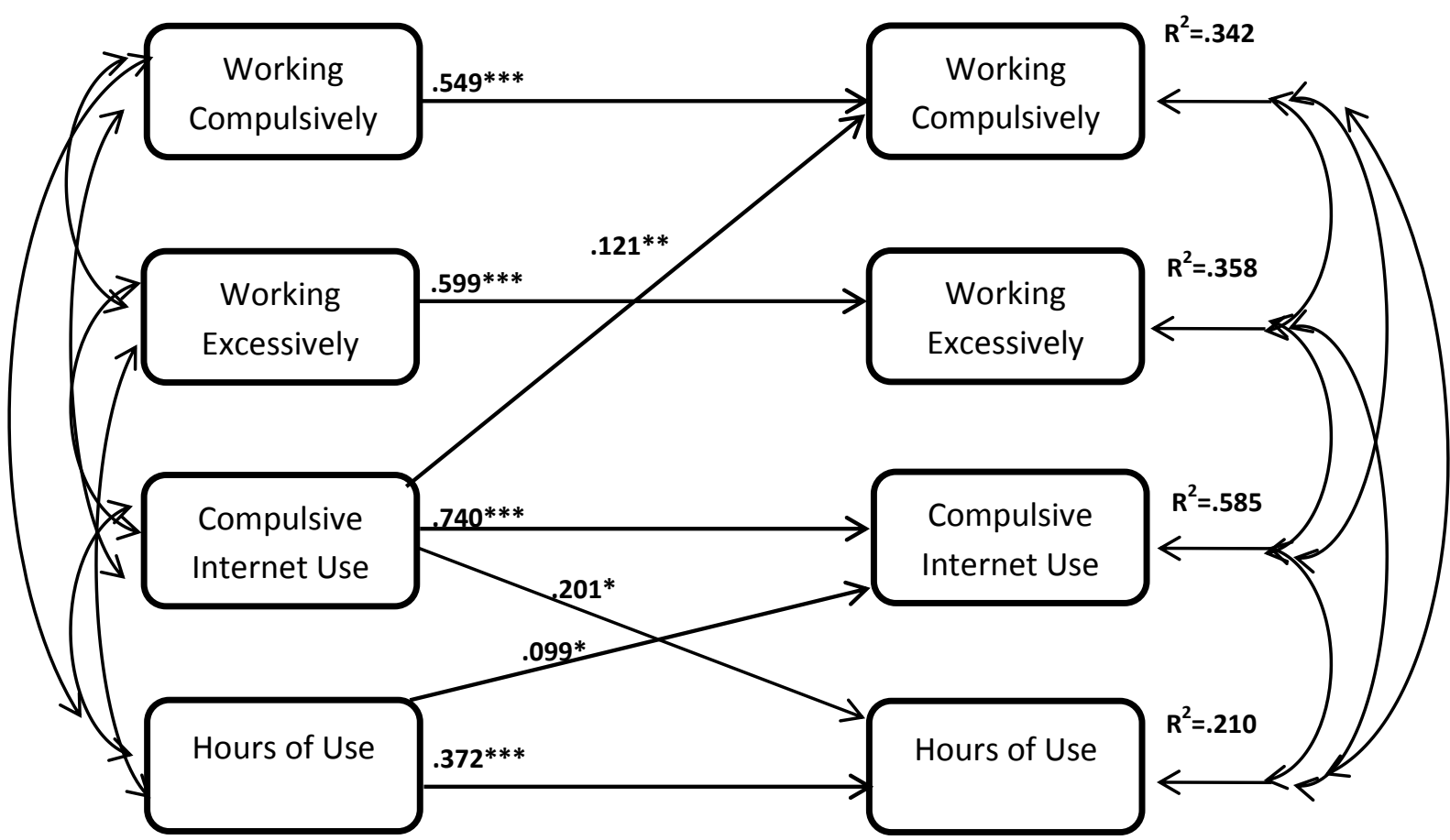

Figure 2. Final cross-lagged structural equation model with standardized coefficients. Coefficients of concurrent correlations and non-significant paths are not depicted. For clarity of presentation, variable have been omitted that did not contribute to explain cross-lagged variance of the variables of study. However the results presented here were estimated controlling for these variables. 
Table 3. Fit Indices and chi-square difference tests of nested path models

\begin{tabular}{|c|c|c|c|c|c|c|c|c|}
\hline Model & $\chi^{2}$ & $D f$ & CFI & RMSEA & AIC & Comparison & $\Delta \chi^{2}$ & $\Delta d f$ \\
\hline No cross-lagged (M1) & 158.11 & 72 & .940 & .070 & 356.11 & M1vs M2 & $8.21 *$ & 1 \\
\hline Cross-lagged CIU $\mathrm{T} 1_{1}-\mathrm{WE}_{\mathrm{T} 2}, \mathrm{WE}_{\mathrm{T} 2}(\mathrm{M} 2)$ & 149.91 & 71 & .945 & .068 & 349.91 & M1 vs M3 & .26 & 1 \\
\hline Cross-lagged $\mathrm{WE}_{\mathrm{T} 1}, \mathrm{WC}_{\mathrm{T} 1}-\mathrm{CIU}_{\mathrm{T} 2}(\mathrm{M} 3)$ & 157.85 & 71 & .940 & .071 & 357.91 & M1 vs M4 & $8.51 *$ & 2 \\
\hline Both cross (M4) & 149.64 & 70 & .945 & .068 & 351.64 & M2 vs M4 & .27 & 1 \\
\hline Cross-lagged Hourst1-CIU 2 (M5) & 143.68 & 69 & .948 & .067 & 347.68 & M2 vs M5 & $6.23 *$ & 2 \\
\hline Cross-lagged CIUT1-Hourst2 (M6) & 137.82 & 69 & .952 & .064 & 341.82 & M2 vs M6 & $17.5^{*}$ & 2 \\
\hline Both cross (M7) & 132.41 & 68 & .959 & .060 & 338.41 & M5 vs M7 & $11.27^{*}$ & 1 \\
\hline \multirow[t]{2}{*}{ Both cross with equality (M8) } & 142.19 & 69 & .949 & .066 & 346.19 & M6 vs M7 & $5.41 *$ & 1 \\
\hline & & & & & & M7 vs M8 & $9.78 *$ & 1 \\
\hline
\end{tabular}




\section{Discussion}

The aim of the present study was to explore the mechanisms under which two compulsive behaviours (i.e., Internet use and work) are increasingly intertwined. The study specifically explored the existence of two ways in which compulsive internet use and compulsive work can be related. In particular, the study tested whether the relationship between these variables was bidirectional (supporting the fusion mechanism) or whether the compulsive Internet use increased the strength of compulsive working (supporting the masking process, whereby a more socially accepted addiction is cultivated as an initial strategy to help hide a less desirable one). Here, spending time online instead of socializing with friends and family was considered the hidden behaviour, as this has negative social connotations to do with nonappropriate age hobby and limited social abilities (Sussman et al., 2014). In contrast, working excessively was considered the more socially acceptable behaviour, as it is encouraged and rewarded in many organizations (Griffiths \& Karanika-Murray, 2012).

The results failed to confirm mutual causation. Instead, the significant cross-lagged path runs from CIU at Time 1 to working compulsively at Time 2. These results lend preliminary support to the idea that for those who are employed and that use the internet as part of their work, the most suitable way to cope with the conflict caused by their excessive online behaviour can be through engaging in a behaviour which is socially acceptable (work) as this, at least initially, helps them minimise that conflict. These results and the lack of reciprocal causation indicate that a masking mechanism would be a more likely explanation as to how these two behaviours relate to each other.

Importantly, it was found that CIU was not related to working excessively. To some extent, these results are in line with previous literature suggesting that the inner drive to work and loss of control (i.e., WC) is the core of workaholism (Bakker, Demerouti, Oerlemans, \& 
Sonnentag, 2012). Similarly, loss of control and behavioural salience are core features of CIU as opposed to engaging in use for long hours, which is also characteristic of high although potentially healthy engagement (Griffiths, 2010b). Indeed there are many instances where high engagement is strongly related to positive health and work outcomes (e.g., Charlton, 2002). A reciprocal relationship was found between hours of use and CIU. However, the path from compulsive Internet use at Time 1 to increased hours at Time 2 was stronger. This pattern is consistent with the tolerance element of addictions whereby more intense engagement is required over time to get the same effects as were initially experienced (Griffiths, 2005; Meerkerk et al., 2010).

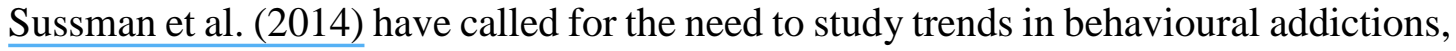
and the co-occurrence of some addictions and not others, in order to develop well-informed and more holistic prevention strategies. The present study addresses this call by looking at two compulsive behaviours that are of high relevance giving the increasing importance of both elements in contemporary workplaces. Although this study requires further replication, these results would suggest that in cases where compulsive Internet use is being treated, special attention should be paid to other unreported or unrecognised behaviours, in this case their relationship with work. There is a risk that if these types of more holistic approaches are not employed, individuals could replace compulsive Internet use with compulsive working in a similar fashion at it occurs with other behavioural and substance-based addictions (Carnes et al., 2005).

Sussman et al. (2014), and others in the CIU literature (e.g. Byun et al., 2009), have also encouraged researchers to conduct different wave studies to overcome the limitations associated with cross-sectional design studies. Although qualitative and cross-sectional quantitative studies have shown significant relationships between workaholism and compulsive Internet use (e.g., Porter \& Kakabadse, 2006; Quinones-Garcia \& Kakabadse, 
2014), to the authors' knowledge, this is the first two-wave longitudinal study to explore the relationships between these constructs.

The study is not without its limitations and these need to be considered when evaluating the value of the study's findings. First, potential scenarios for co-occurrence may involve a third unaccounted variable that causes them both. Although the study attempted to limit this by controlling relevant personality traits such as neuroticism, another key correlate of CIU which was not included here is rash impulsivity (Meerkerk et al., 2010; Mottram \& Fleming, 2009). Considering the impact on resources and the desire to limit participant overload, only a small number of control variables could be used and the criteria to select them was that they were key explanatory variables to the two focal variables (i.e., working compulsively and excessively, and compulsive Internet use). Considering that neuroticism - and not impulsivity - is a key predictor of the present authors' conceptualization of workaholism (e.g. Sharma \& Sharma, 2011; Aziz \& Tronzo, 2011), this was selected as the control variable. It should also be noted that the reliability of the short Big Five measure was relatively low particularly in the Openness scale. However, this should not have been a problem as the content and predictive validity of the scales has been extensively supported particularly with anxiety and stress-related variables (Christiansen et al., 2014; Donnel et al., 2006), and variables in the present study are related to these type of variables.

Another limitation is that the data were all self-report and therefore subject to wellknown biases (e.g., social desirability biases, recall biases). A related limitation is that the sample size was modest and the two-wave design does not allow the confirming of causality. However, the design used here improves the significance of the predictions compared to other self-report and cross-sectional designs, which are highly prevalent in existing behavioural addictions research. A final limitation is that participants were all panellists from a market research company. This lack of representativeness may have affected the results, however, 
owing to the widespread Internet use in the UK, the present authors are confident that these participants were not significantly heavier Internet users than the general population.

Although the actual mechanisms explaining the co-occurrence are likely to involve a complex myriad of factors, the study provides preliminary evidence concerning the potential operating mechanisms. Further longitudinal studies are needed to more adequately investigate drivers and develop sound prevention strategies that also include compulsive traits as controls. The use of qualitative methods is also encouraged to explore compulsive Internet users' experience of conflict and whether work is an actual "masking" strategy" for these individuals. Another future line of enquiry is to replicate the study but only with individuals that have relatively high levels of CIU, a larger effect in those cases would be expected.

In short, these results suggest that the risk of developing a maladaptive use of the Internet seems to increase with high Internet use, which in turn, increases the likelihood of developing maladaptive relationships with one's work. At a time of growing work intensification when both work and leisure activities are largely supported or engaged online, an understanding of how these two behaviours may sometime interact to trigger problems is highly valuable in the field of occupational health psychology. This increased awareness can help achieve a more healthy engagement in both behaviours and help develop holistic interventions to a variety of compulsive behaviours. 


\section{References}

Andreassen, C. S., Griffiths, M. D., Hetland, J., Kravina, L., Jensen, F., \& Pallesen, S. (2014). The prevalence of workaholism: A survey study in a nationally representative sample of Norwegian employees. PLoS ONE, 9(8): e102446. doi:10.1371/journal.pone.0102446.

Andreassen, C. S., Griffiths, M. D., Hetland, J. \& Pallesen, S. (2012). Development of a Work Addiction Scale. Scandinavian Journal of Psychology, 53, 265-272.

Andreassen, C. S., Ursin, H., \& Eriksen, H. R. (2007). The relationship between strong motivation to work, "workaholism," and health. Psychology and Health, 22, 625-629.

Aziz, S., \& Tronzo, C. L. (2011). Exploring the relationship between workaholism facets and personality traits: A replication in American workers. Psychological Record, 61, 269276.

Bakker, B., Burke, R., \& Demerouti, E. (2009).Workaholism and Relationship Quality: A Spillover-Crossover Perspective. Journal of Occupational Health Psychology, 14, 2333. DOI: $10.1037 / \mathrm{a} 0013290$

Bakker, B. Demerouti, E., Oerlemans, W., \& Sonnentag, S. (2012). Workaholism and daily recovery: A day reconstruction study of leisure activities. Journal of Organizational Behavior, 34, 87-107. DOI: 10.1002/job.1796

Barber, L. K., \& Jenkins, J. S. (2014). Creating technological boundaries to protect bedtime: Examining work-home boundary management, psychological detachment and sleep. Stress and Health, 30, 259-264.

Burke, R. J. (2001). Predictors of workaholism components and behaviors. International Journal of Stress Management, 8, 113-127. 
Burkholder, G.J. \& Harlow, L.L. (2003). An Illustration of a Longitudinal Cross-Lagged Design for Larger Structural Equation Models. Structural Equation Modeling: A Multidisciplinary Journal,10, 465-486.

Byun, S., Ruffini, C., Mills, J. E., Douglas, A. C., Niang, M., Stepchenkova, S., Lee, S. K., Loufti, J., Lee, J.-K., Atallah, M., \& Blanton, M. (2009). Internet addiction: Metasynthesis of 1996-2006 quantitative research. CyberPsychology \& Behavior, 12(2), 203-207.

Charlton, J. P. (2002). A factor-analytic investigation of computer 'addiction' and engagement. British Journal of Psychology, 93(3), 329-344.

Charlton, J. P., \& Danforth, I. D. W. (2009). Distinguishing addiction and high engagement in the context of online game playing. Computers in Human Behavior, 23, 1531-1548.

Christiansen, N., Sliter, M., \& Frost, C.T. (2014).What employees dislike about their jobs: $\underline{\text { Relationship between personality-based fit and work satisfaction. Personality and }}$ Individual Differences, 71, 25-29.

Carnes, P. J., Murray, R. E., \& Charpentier, L. (2005). Bargains with chaos: Sex addicts and addiction interaction disorder. Sexual Addiction \& Compulsivity, 12(2-3), 79-120. doi: $10.1080 / 10720160500201371$

Casale, S., Fioravanti, G., Flett, G. L., \& Hewitt, P. L. (2015). Self-presentation styles and Problematic use of Internet communicative services: The role of the concerns over behavioral displays of imperfection. Personality and Individual Differences, 76, 187192.

Davis, R. A. (2001). A cognitive--behavioral model of pathological Internet use. Computers in Human Behavior, 17, 187-195. 
De Langue, A. H., Taris, T. W., Kompiers, M. A. J., Houtman, I. D., \& Bongers, P. M. (2004). The relationships between work characteristics and mental health: Examining normal, reversed and reciprocal relationships in a 4-wave study. Work \& Stress, 18(2), 149-166.

Derks, D., van Mierlo, H., \& Schmitz, E. B. (2014). A diary study on work-related smartphone use, psychological detachment and exhaustion: Examining the role of the perceived segmentation norm. Journal of Occupational Health Psychology, 19, 74-84. doi:10.1037/a0035076

Donnellan, M. B., Oswald, F. L., Baird, B. M., \& Lucas, R. E. (2006). The mini-IPIP scales: tiny-yet-effective measures of the Big Five factors of personality. Psychological Assessment, 18, 192-203.

Goodman, J. S. \& Blum, T. C. (1996). Assessing the non-random sampling effects of subject attrition in longitudinal research. Journal of Management, 22, 627-652.

Grant, J. E., Potenza, M. N., Weinstein, A. \& Gorelick, D. A. (2010). Introduction to behavioral addictions. Americal Journal of Drug and Alcohol Abuse, 36(5), 233-241.

Greenfield, D. N. (1999). Psychological characteristics of compulsive Internet use: A preliminary analysis. CyberPsychology \& Behavior, 2(5), 403-412.

Griffiths, M. (2000). Does Internet and Computer Addiction "Exist"? Some case study evidence. CyberPsychology \& Behavior, 3(2): 211-218.

Griffiths, M. D. (2005). A 'components' model of addiction within a biopsychosocial framework. Journal of Substance Use, 10, 191-197.

Griffiths, M. D. (2010a). Internet abuse and internet addiction in the workplace. Journal of Workplace, 22(7), 463 - 472.

Griffiths, M. D. (2010b). The role of context in online gaming excess and addiction: Some case study evidence. International Journal of Mental Health and Addiction, 8, 119-125. 
Griffiths, M. D. \& Karanika-Murray, M. (2012). Contextualising over-engagement in work: Towards a more global understanding of workaholism as an addiction. Journal of Behavioral Addictions, 1(3), 87-95.

Kakabadse, N., Kouzmin, A., \& Kakabadse, A. (2000). Technostress: Over identification with information technology and its impact on employees and managerial effectiveness, in Kakabadse, A., \& Kakabadse, N. (Eds.), Creating Futures: Leading Change Through Information Systems (pp. 259-296). Aldershot: Ashgate.

Knight, S. (2011). Digital literacy can boost employability and improve student experience. Available at: $\quad$ http://www.theguardian.com/higher-educationnetwork/blog/2011/dec/15/digital-literacy-employability-student-experience. [accessed December 2014].

Kuss, D. J., Griffiths, M. D., Karila, L., \& Billieux, J. (2014). Internet Addiction: A Systematic $\underline{\text { Review of Epidemiological Research for the Last Decade. Current Pharmaceutical }}$ Design, 20, 4026-4052.

Landers, R. N., \& Lounsbury, J. W. (2006). An investigation of Big Five and narrow personality traits in relation to Internet usage. Computers in Human Behavior, 22(2), 283-293.

Lin, X., \& Leung, K. (2010). Differing effects of coping strategies on mental health during prolonged unemployment: A longitudinal analysis. Human Relations, 63, 637-655.

Maitland, A. \& Thomson, P. (2011). Future Work. How businesses can adapt and thrive in the new world of work. Palgrave MacMillan.

Mazmanian, M. A., Orlikowski, W. J., \& Yates, J. (2013). The autonomy paradox: The implications of mobile email devices for knowledge professionals. Organization Science, 24, 1337-1357. doi:10.1287/orsc.1120.0806 
McKinsey Global Institute (2011). Internet matters: The Net's sweeping impact on growth, jobs and prosperity. Available at www.mckinsey.com/mgi [accessed January 2015].

Meerkerk, G., van den Eijnden, R. J. J. M., Franken, I. H. A., \& Garretsen, H. F. L. (2010). Is compulsive internet use related to sensitivity to reward and punishment, and impulsivity? Computers in Human Behavior, 26, 729-735.

Miller, W.R. (1980), "The addictive behaviors", in Miller, W.R. (Ed.), The addictive behaviors: Treatment of alcoholism, drug abuse, smoking and obesity. Pergamon Press, New York, NY.

Mottram, A., \& Fleming, M. (2009). Extraversion, impulsivity, and online group membership as predictors of problematic Internet use. Cyberpsychology \& Behavior, 12, 319-321

Ng, T.W.H., Sorensen, K.L., \& Feldman, D.C. (2007). Dimensions, antecedents, and consequences of workaholism: A conceptual integration and extension. Journal of Organizational Behavior, 28, 111-136.

Nithya, H. H., \& Julius, S. (2007). Extroversion, neuroticism and self-concept: their impact on internet users in India. Computers in Human Behavior, 23(3), 1322-1328.

Oates, W. (1971). Confessions of a workaholic: The facts about work addiction. New York: World.

Orford, J. (2001). Excessive appetites: A psychological view of addictions (Second edition). Chichester: John Wiley.

Porter, G. (2001), Workaholics as high-performing employees: the intersection of workplace and family relationship problems, in Robinson, B. and Chase, N. (Eds), High Performing Families: Causes, Consequences, and Clinical Solutions - A Monograph in the American Counseling Association's Family Psychology. 
Porter, G. \& Kakabadse, N.K. (2003). An addictive perspective on technology and work, Proceedings of the International Human Resource Management Conference, Limerick, June.

Porter, G., \& Kakabadse, N. K. (2006). HRM perspectives on addiction to technology and work. Journal of Management Development, 25, 535-560. doi:10.1108/02621710610670119

Quinones \& Kakabadse, N (2015). Self-concept clarity, social support, and compulsive internet use: A study of the USA and the UAE. Computers in Human Behavior, 44,347-356.

Richardson, K. M., \& Benbunan-Fich, R. (2011). Examining the antecedents of work connectivity behavior during non-work time. Information and Organization, 21, 142160. doi:10.1016/j.infoandorg.2011.06.002

Schaufeli, W.B., Bakker, A.B., van der Heijden, F.M.M., \& Prins, J.T. (2009a) Workaholism among medical residents: It is the combination of working excessively and compulsively that counts. International Journal of Stress Management, 16(4), 249-272

Schaufeli, W. B., Shimazu, A., \& Taris, T. W. (2009b). Being driven to work excessively hard: The evaluation of a two-factor measure of workaholism in Japan and the Netherlands. Cross-Cultural Research, 43, 320-348.

Schumacker, R. E. \& Lomax, R. G. (1996). A beginner's guide to structural equation modeling. Mahwah, New Jersey: Lawrence Erlbaum Associates, Publishers.

Schwartz, Shalom H.(2010).Basic values: How they motivate and inhibit prosocial behavior. Mikulincer, Mario (Ed); Shaver, Phillip R. (Ed), (2010). Prosocial motives, emotions, and behavior: The better angels of our nature. , (pp. 221-241). Washington, DC, US: American Psychological Association, xiv, 468 pp. http://dx.doi.org/10.1037/12061012 
Shaffer, H. J., LaPlante, D. A., LaBrie, R. A., Kidman, K. C., Donato, A. N., \& Stanton, M. V. (2004). Toward a syndrome model of addiction: Multiple expressions, common etiology. Harvard Review of Psychiatry, 12, 367-374.

Sharma, J., \& Sharma, P. (2011). Workaholism and its correlates: A study of academicians. International Journal of Management and Business Research, 1(3), 151$\underline{160 .}$

Sherry, S.B., Gautreu, C.M., Mushquash, A.R., Sherry, D.L. \& Allen, S.A. (2014).Self-critical perfectionism confers vulnerability to depression after controlling for neuroticism: A longitudinal study of middle-aged, community-dwelling women. Personality and Individual Differences, 69, 1-4.

Sonnentag, S., Binnewies C, Mojza E.J. (2008). Did You Have A Nice Evening? A Day-Level Study on Recovery Experiences, Sleep, and Affect. Journal of Applied Psychology,93,3, 674-684.

Sussman, S., Arpawong, T. E. M., Sun, P., Tsai, J., Rohrbach, L. A., \& Sprutjt-Metz, D. (2014). Prevalence and co-occurrence of addictive behaviors among former alternative high school youth. Journal of Behavioral Addictions, 3(1), 33-40. doi: DOI: 10.1556/JBA.3.2014.005

Sussman, S., Lisha, N., \& Griffiths, M. (2011). Prevalence of the addictions: A problem of the majority or the minority? Evaluation and the Health Professions, 34(1), 3-56. doi: $10.1177 / 0163278710380124$

Sussman, S., \& Sussman, A. (2012). Considering the definition of addiction. International Journal of Environmental Research and Public Health, 8, 4025-4038.

Van Beek, I., Taris, T.W., \& Schaufeli, W.B. (2011). Workaholic and work engaged employees: Dead ringers or worlds apart? Journal of Occupational Health Psychology, $16,468-482$ 
Van der Aa, N., Overbeek, G., Rutger, C. M. E., Engels, Scholte, R. H. J., Meerkerk, G.-J., Van den Eijnden, R. J. J. M. (2009). Daily and compulsive internet use and well-being in adolescence: A diathesis-stress model based on Big Five personality traits. Journal of Youth Adolescence (2009) 38:765-776. DOI 10.1007/s10964-008-9298-3

Volkow, N., \& Li, T.-K. (2005). The neuroscience of addiction. Nature neuroscience, 8, 11, 1429-1931.

Young, K. \& R. C. Rogers (1998). The Relationship Between Depression and Internet Addiction. CyberPsychology \& Behavior, 1(1): 25-28.

Zacher, H. \& de Lange, A. H. (2011). Relations between chronic regulatory focus and future time perspective: Results of a cross-lagged structural equation model. Personality and Individual Differences, 50, 1255-1260. 